DR. AJAY KEVAT (Orcid ID : 0000-0001-9881-6478)

DR. ATUL MALHOTRA (Orcid ID : 0000-0001-9664-4182)

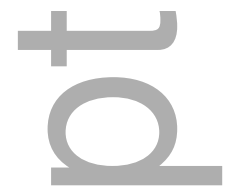

Article type : Review Article

Review Article

Digital stethoscopes in paediatric medicine

Ashwin Ramanathan ${ }^{1}$, Lindsay Zhou ${ }^{2}$, Faezeh Marzbanrad ${ }^{3}$, Robert Roseby ${ }^{1,4}$, Kenneth Tan ${ }^{1,2,5},{ }^{*}$ Ajay Kevat $^{1},{ }^{*}$ Atul Malhotra ${ }^{1,2,5}$

${ }^{1}$ Department of Paediatrics, Monash University, Melbourne, Australia

${ }^{2}$ Monash Newborn, Monash Children's Hospital, Melbourne, Australia

${ }^{3}$ Department of Electrical and Computer Systems Engineering, Monash University, Melbourne,

Australia

${ }^{4}$ Department of Paediatric Respiratory Medicine, Monash Children's Hospital, Melbourne, Australia

${ }^{5}$ The Ritchie Centre, Hudson Institute of Medical Research, Melbourne, Australia

*Equal contribution

Short title: Digital stethoscopes

Corresponding Author:

Dr Atul Malhotra

Monash Children's Hospital

246 Clayton Road,

This is the author manuscript accepted for publication and has undergone full peer review but has not been through the copyediting, typesetting, pagination and proofreading process, which may lead to differences between this version and the Version of Record. Please cite this article as doi: 10.1111/apa.14686

This article is protected by copyright. All rights reserved 
Clayton VIC 3168, Australia

Tel: +61385723650

Fax: +61385723649

Email: atul.malhotra@monash.edu

Abstract

Aim: To explore, synthesise and discuss currently available digital stethoscopes (DS) and the evidence for their use in paediatric medicine. Methods: Systematic review and narrative synthesis of digital stethoscope use in paediatrics following searches of OVID Medline, Embase, Scopus, PubMed and Google Scholar databases. Results: Six digital stethoscope makes were identified to have been used in paediatric focused studies so far. A total of 25 studies of DS use in paediatrics were included. We discuss the use of digital stethoscope technology in current paediatric medicine, comment on the technical properties of the available devices, the effectiveness and limitations of this technology, and potential uses in the fields of paediatrics and neonatology, from telemedicine to computer aided diagnostics. Conclusion: Further validation and testing of available DS devices is required.

Comparison studies between different types of DS would be useful in identifying strengths and flaws of each DS as well as identifying clinical situations for which each may be most appropriately suited.

\section{Key Notes}

1. Auscultation devices are undergoing technological advances evident through the introduction of digital stethoscopes.

2. Digital stethoscopes offer potential development to diagnostic devices without listener subjectivity constraints as in traditional auscultation techniques.

3. Potential uses of digital stethoscope technology include: telemedicine for increasing specialist access; computer aided diagnostic programs/algorithms for accurate clinical diagnosis based on auscultation; home-based monitoring of cardiorespiratory conditions; clinical teaching.

\section{Keywords}

Infant; Newborn; Telemedicine; Signal processing; Computer-Assisted Phonocardiography

\section{Introduction}

This article is protected by copyright. All rights reserved 
Rene Theophile Hyacinthe Laënnec invented the stethoscope in 1816 to aid physicians in listening to the workings of the internal body in a professionally appropriate manner $(1,2)$. More than 200 years later, the stethoscope is arguably the most iconic symbol of the medical profession. Although basic design changes have taken place over this time, the inherent acoustic properties of the stethoscope remained unchanged until the digital revolution, which has brought with it the introduction of the digital stethoscope. In this review article, we discuss the evolution of the stethoscope to this modern form, review the current range of electronic stethoscopes available, describe the utilisation of this technology in paediatric as well as neonatal medicine, and outline potential uses in future practice.

\section{The Acoustic Stethoscope}

The binaural acoustic stethoscope is the iteration of the stethoscope used most abundantly by medical practitioners currently. It functions simplistically on the transmission of sound waves captured through vibrations of the diaphragm of the chest piece contacting the surface of the skin. The sound is transmitted via the hollow tubing connecting the head of the stethoscope to the earpieces. Most acoustic stethoscopes will comprise of a diaphragm and bell chest piece, which operate to transmit different frequency ranges of heart and lung sounds (3).

Variations in acoustic stethoscope composition can alter the sound quality to some degree, for example through alterations in tubing length and material, presence of single or double tubing, and the depth and diameter of the diaphragm and bell components of the device. In some studies, double tubing was associated with greater sound transmission, with single-tubed stethoscopes producing irregular frequency responses (4). Other studies found no significant practical advantage of a double tubed device compared to a single tube (3). There is general consensus however that for traditional binaural stethoscopes, a properly sealed acoustic pathway is vitally important for optimising sound quality and frequency ranges transmitted (3-5).

Nevertheless, regardless of design, acoustic stethoscopes display a loss or alteration of high frequency tones. These are not only important in localisation of sounds and harmonics (4), but may also be associated with specific murmurs or respiratory pathologies $(4,6)$. Compromise of these frequency ranges in auscultation could therefore result in pathological sounds going unheard and undiagnosed. The incidence of failing to hear pathological high frequency sounds may be increased by presbycusis (7).

\section{The Digital Stethoscope}

Digital stethoscopes (DS) are generally superior to acoustic stethoscopes in their ability to convey a wide spectrum of sound waves. They do this by capturing sounds obtained from the diaphragm and 
transmitting them electronically, rather than through acoustic vibrations. This electronic process enables the sound to be amplified and/or filtered before being converted back to sound waves for transmission to the clinician's ears. In addition, visual displays of the sound can be generated on a smartphone, tablet or computer. These are commonly phonocardiographic or spectrographic in nature, and can be offered in "real-time", meaning the clinician receives them at the time of auscultation with the consequent ability to make auscultation technique adjustments in response.

DS have many useful applications in medical practice. They may be used in lieu of binaural stethoscopes in daily patient care and can facilitate academic teaching in paediatrics (8). They have been successfully employed in medical research and have telehealth applications (9). They can also be augmented by computer software to increase diagnostic capability, although accurate diagnosis based on signal processing and/or deep learning algorithms is not currently available (10).

Digital phonocardiograms recorded via DS were an effective means of increasing auscultatory skills of paediatric clinicians (11). Telemedicine is an important and innovative area with the immense potential for operation in rural and isolated locations, or low resource settings where access to specialised medical care such as paediatric cardiologists or respiratory physicians may not be easily accessible. Telemedicine use in the paediatric population with cardiac auscultation recordings from electronic stethoscopes has already been shown to be feasible and effective for online diagnosis without the presence of the specialist at the bedside $(12,13)$, and has been expanded for use in teaching medical students cardiovascular examination remotely (8). In one study, telemedicine consultations for the monitoring of children with asthma via DS achieved comparable levels of satisfaction and outcomes in terms of asthma control when compared with in-person consultations (14). In the near future, the DS may become a device able to aid the diagnosis of pneumonia in children in low resource settings, through the development of advanced computer algorithms (which is already underway) (15).

A key drawcard of an electronic stethoscope is its amplification and sound filtering capabilities. This capability has been tested in in-flight medical evacuation, an environment with immense background sound interference $(16,17)$. This is an environment in which medical care frequently is necessary, but auscultation is almost impossible due to the noise of the helicopter or aircraft. In this setting, electronic stethoscopes were shown to be capable of enhancing the emergency clinician's ability to auscultate both heart $(16,17)$ and respiratory $(16)$ sounds, through ambient noise reduction and amplification of relevant sounds.

Despite this, as with the conventional acoustic stethoscope, the interpretation of clinician-received sounds from digital stethoscopes remains subjective in nature, as diagnosis is still dependent on the 
listener's ability to correlate sounds with medical conditions. This longstanding limitation of stethoscopes may be overcome when high-quality digital sound capture can be coupled with accurate computerised algorithms, facilitating non-invasive, cost-effective and reliable diagnosis.

\section{Types of Digital Stethoscope}

A variety of DS are currently available. As an emerging technology, it is likely that the capability and availability of different devices will change significantly over time. Two authors (AR, LZ) systematically searched the following databases: OVID Medline, Embase, Scopus, PubMed and Google Scholar to identify relevant studies utilising DS. We used the search terms: digital stethoscope OR electronic stethoscope; AND newborn OR neonate OR infant OR paediatric OR children. The search criteria used resulted in a total of 76 studies. 49 articles were excluded after close review as they were either published in a language other than English, utilised a noncommercially available recording apparatus, were computer or sound engineering based (and not clinical), or were animal studies. The main commercially available DS that have been studied in published literature have been briefly discussed below (Table 1):

\section{M Littman Electronic Model 3200/4000}

The Littman Model 3200 (3M, Maplewood, Minnesota, USA) stethoscope is probably the most wellknown and purchased electronic stethoscope worldwide (18).

The diagnostic capabilities of student doctors when equipped with a standard acoustic stethoscope and a Littman 3200 DS were compared, and found convincing improvements in diagnostic accuracy in the students using the Littman digital stethoscope (19). The Littman 3200 in conjunction with computer algorithms has been used effectively for diagnosis in clinical studies to define pathology in the pulmonary artery $(20,21)$, specify cardiac murmurs $(22)$ and detect adventitious respiratory sounds in paediatric patients (23). The Littman DS was also used in the newborn to assess gut motility patterns (24).

\section{Thinklabs Digital Stethoscope}

The Thinklabs One Digital Stethoscope (Thinklabs, Centennial, Colorado, USA) was designed as a small, portable, tube-free device for clinicians (25).

The Thinklabs DS has been used in trials investigating the accuracy of cardiac murmur detection and diagnosis in children made by specialists via telemedicine (13). In the respiratory field, this stethoscope has effectively been implemented to describe the frequency characteristics of normal pulmonary sounds in the paediatric population, and was successful in describing a difference in 
sound characteristics between various parameters such as age, height and weight (26). Further to this it has been used in the detection of pneumonia (27). Features associated with swallowing in newborns has also been described (28). Interestingly, this DS has also been used antenatally, to record and characterise abdominal sounds of pregnant women across multiple gestations (29).

\section{Clinicloud Digital Stethoscope}

The Clinicloud Digital Stethoscope (Clinicloud, Melbourne, Australia) is a Melbourne-designed and manufactured product that was created with the intention of being a low-cost user-friendly device targeted at the parent demographic, with the purpose of enabling parents to easily record heart and lung sounds of their child (30).

The Clinicloud DS has recently been used in clinical trials in tertiary hospitals in Melbourne, Australia. It proved to be an accurate and feasible apparatus for detecting abnormal lung sounds in children and for determining heart rate in newborns (31-33).

ViScope Digital Stethoscope

The ViScope Digital Stethoscope (HD Medical, Silicon Valley, California, USA) has a unique inbuilt phonocardiogram visual display, allowing for dynamic auscultation (34).

This device was used to investigate the correlation between the amplitude of the first heart sound and left ventricular function. The ViScope DS was shown to be advantageous as an accessible and portable bedside diagnostic tool, useful for evaluating left ventricular systolic function (35).

\section{EkoCore and EkoDuo Digital Stethoscopes}

The EkoCore Stethoscope (Eko Devices, Berkeley, California, USA) is unique in that it is a hybrid device which has the capability to operate as a traditional acoustic stethoscope or as an electronic stethoscope. Eko Devices also offers an attachment, compatible with most acoustic stethoscopes, which connects to and digitalises the acoustic stethoscope. This DS is currently being further advanced with the introduction of the EkoDuo, a device that focuses on cardiac auscultation at the bedside. It combines digital stethoscope with a one-lead ECG, which may be displayed in real-time (36).

Only one study has utilised this device to auscultate various murmur types and compare the accuracy of physician diagnosis using traditional auscultation methods compared to the DS (37).

Meditron/Meditron M30 Stethoscope 
The Meditron Stethoscope (Meditron ASA, Oslo, Norway) was developed in 2001 and was at one stage partnered with Welch Allyn (The Stethoscope) (38).

The Meditron DS has been used in conjunction with automated systems to discriminate between pathological and innocent heart murmurs in children (39) as well as clinician diagnosis over telemedicine (12).

In summary, a variety of DS are currently available and offer unique additions to the prospect of easing medical diagnosis for the clinician. The Thinklabs, Littman, Clinicloud, ViScope, Eko and Meditron DS have all been utilised in clinical research. There may be other brands of DS commercially available in addition to this list.

\section{Digital Stethoscope use in Paediatrics (Table 2)}

\section{Cardiac applications}

In recent years, there has been growing interest in the use of DS in paediatrics. A number of studies have investigated the accuracy of utilising electronic and DS technology to detect murmurs as well as differentiate innocent ones from those that are pathological. These studies produced phonocardiograms from the acquired heart sound recordings and evaluated the ability of medical professionals to interpret these accurately, often against a gold-standard measure of diagnosis such as echocardiogram $(12,22,40-43)$. In addition, DS has also been used to develop computerised algorithms for recognition of heart sounds and murmurs (44). Heart sound recordings have also been coupled with artificial neural networks for the same purpose of differentiating pathological from innocent murmurs (45). These systems may allow efficient and effective diagnosis without inter-listener discrepancies.

DS technology has also been used to assess pulmonary artery hypertension (PAH). Frequency analysis on heart sound recordings displayed distinct characteristics found in children with PAH when compared to controls $(20,21)$. This analysis allowed for the non-invasive demonstration of a unique visual signature for this specific condition (46), demonstrating that digital auscultation may be effective in differentiating children with PAH from those with a normal pulmonary artery pressure. This could prove to be useful as a diagnostic tool.

\section{Respiratory applications}

Use of DS and accompanied sound analysis has been useful in characterising the unique sound variations in different patient populations and disease states. The Thinklabs DS was utilised to investigate baseline spectral parameters of non-pathological respiratory sounds in the young 
paediatric population. Respiratory sound parameters were found to be related to age, height and weight, confirming findings of earlier investigations $(26,47,48)$.

DS technology has also been applied to the detection of abnormal breath sounds, such as wheeze and crackles, in children. The ability to detect abnormal sounds using an electronic stethoscope was shown to be improved in comparison to an experienced doctor's auscultation with an acoustic stethoscope in one small study (33). In another investigation, a DS was used to assess preschool age children with a confirmed radiographic diagnosis of pneumonia. Although sensitivity for detection of pneumonia through crepitation detection was only $56 \%$ in comparison to plain chest x-ray, the research displays a novel use for the technology as a bedside assessment tool (27). This was followed by a large multi-country case-control study across Africa and Asia where the same technology was used again to identify abnormal pulmonary sounds in paediatric cases of pneumonia (49). The study concluded that use of this technology in low-resource settings is feasible and interpretations from the sound recordings can reliably be achieved.

\section{Digital Stethoscope use in Neonatology}

As heart rate (HR) plays a major role in the determination of intervention and/or resuscitation requirements, especially at birth, the focus of clinical studies of DS applied to the neonatal population so far has focussed on accurate detection of this vital sign. Electronic stethoscopes offer an alternative to the widespread auscultatory or palpatory methods of acquiring HR from a newborn. The Clinicloud DS with smartphone heart rate detection algorithm has been shown to have greater accuracy than chest auscultation and cord palpation in determining newborn HR by two and three-fold respectively $(32,50)$. The feasibility of utilising this device in the transitioning infant within the delivery room has also been examined. Accurate and non-invasive determination of HR with strong correlation with ECG was possible (31). Compared to the Littman 3200, the Clinicloud DS dictates a more accurate HR reading (51). Difficulty producing an accurate HR reading during crying episodes was cited as a limitation of the device in this particular patient population.

The only other study involving this mode of technology and analysis in the transitioning newborn dates back to the late 1990s where Shirota et al. utilised a customised microphone, amplifier and recording system, comparable to an early form of a custom-built DS. This study investigated differences in the sound wave characteristics of breath sounds of infants born via caesarean section and the vaginal route. It was hypothesised that frequency bands of breath sounds in the transitioning infant would increase with larger volumes of lung fluid. Lung sounds at multiple intervals over a 72-hour period were recorded, and it was observed that in caesarean deliveries, the 
frequency of the sounds began to decline close to 72 hours post-birth, as opposed to vaginally delivered newborns, who showed a decline by 48 hours(52).

DS has been used to monitor abdominal sounds in neonates (53) and was able to describe the frequencies of bowel sounds in relation to feeding, which allow the assessment of bowel motility patterns in newborns (24). This technology was evaluated as a means of commenting on feeding maturation in newborns. By recording the sounds associated with swallowing, features such as frequency and rhythm of swallows were able to be correlated with gestation of the newborn (28).

\section{Artificial Neural Networks}

Artificial neural networks (ANN) are computer systems designed to detect patterns within a dataset and draw conclusions based on trained algorithms. These systems are being applied to digital recordings of heart and lung sounds via a DS to produce automated clinical diagnoses. Many algorithms have been developed to date with varying levels of accuracy. One such ANN was able to obtain $100 \%$ sensitivity and specificity for correctly distinguishing between innocent and pathological murmurs (45), while an ANN designed to detect adventitious respiratory sounds obtained an accuracy of $95.12 \%$ (23). ANNs to detect specific diagnoses such as pneumonia are currently being trialled $(10,15)$. The definitive development of robust algorithms would strengthen the benefits of ANN and DS as an interpretation tool in routine clinical practice.

\section{Limitations of Digital Stethoscopes}

It should be noted that each brand of DS is unique therefore holds individual product limitations. As a technology, there are some overall limitations to the use in clinical medicine. For the purpose of diagnosis, the DS device alone has no ability to identify pathology or abnormal sounds. It simply acts as a recording instrument and in some cases may visually display the sound in the form of a phonocardiogram. Automated diagnosis is only possible with the development and accompaniment of computer algorithms. With automated systems there is an expected rate of false positives and false negatives that could occur. In the majority of studies available, the methodology describes a single chest recording. However, this is often insufficient for the purpose of complex diagnosis. The requirement of multiple auscultation points may introduce further error.

Whilst these devices are easy to use and require very minimal to no training to operate, the quality of sound recordings may vary with usage. Some of the brands such as the Clinicloud DS do not offer real-time listening, so the sound can only be evaluated post recording. DS technology is without question opening new gates to the clinician's ability to monitor or assess pulmonary, cardiac and 
bowel sounds in particular. There may be concern however, as to the possibility or extent of loss of auscultation skill that may occur due to the automated nature of these devices.

\section{Future of Digital Stethoscope use}

Recently, interest in digitalising the traditional stethoscope has grown and is leading to further development in patient monitoring and diagnostic capabilities. The scope of potential benefits this technology may impart upon paediatric medicine is still unknown, and there are many areas yet to be explored. Currently, it would appear the main area of use for these devices are in the classification of cardiac auscultation, including the recognition of murmur aetiology. Pathology in the newborn is yet to be investigated. Considering the well-documented shift from paper-based to electronic medical records underway in many healthcare settings (54), this technology may have a role in standard practice for data recording and data-sharing in patient care. The need for frequent reassessment and repeated auscultation by multiple clinicians may be reduced by a single recording being made accessible to any member of the treating team, uploaded to the patients' electronic medical record (55). Large databases of heart sound recordings and phonocardiograms have been established in adult medicine, with the potential for the development of clinical decision support systems from this data (56). There is the opportunity to extend this into a paediatric and neonatal database of sound. Application to the burgeoning field of telemedicine has already begun; DS have been shown to be both practical and effective in telehealth in multiple studies (12-14). The potential implications of being able to easily record and transmit patient sound recordings from one location to another are significant. Access to specialist care in rural and remote regions continues to require further attention and innovation. In the future, more efficient and accurate diagnosis is a key advantage the DS and associated software may offer.

Accuracy and consistency of current more traditional auscultation techniques are sub-optimal (57), and as low as $20 \%$ correct identification of cardiac abnormality among clinicians has been reported (58). Not only do DS carry the potential to advance the teaching abilities of medical faculties (19), they also possess the capability to remove the user-dependant error with the development of artificial neural networks and the amalgamation of these technologies to create an automated diagnostic program $(45,59)$.

Further validation and testing of these devices is required. Comparison studies between available models of DS would be useful in identifying strengths and flaws of each as well as identifying clinical situations for which each DS may be most appropriately suited. It is likely that the next decade will see significant advances in the use of DS, and we predict they will have a role in routine clinical practice.

This article is protected by copyright. All rights reserved 


\section{List of abbreviations}

DS - Digital Stethoscope/s

HR - Heart Rate

PAH - Pulmonary Artery Hypertension

\section{Conflict of interest and funding}

We declare that none of the authors have any conflicts of interest or disclosures to declare. No author holds any interest in any of the commercially available stethoscope companies. Dr Atul Malhotra is supported by a Royal Australasian College of Physicians Fellowship.

\section{References}

1. Roguin A. Rene Theophile Hyacinthe Laënnec (1781-1826): The Man Behind the Stethoscope. Clin Med Res 2006; 4: 230-5.

2. Sakula A. R T H Laennec 1781--1826 his life and work: a bicentenary appreciation. Thorax 1981; 36: 81-90.

3. Kindig JR, Beeson TP, Campbell RW, Andries F, Tavel ME. Acoustical performance of the stethoscope: A comparative analysis. Am Heart J 1982; 104: 269-75.

4. Ertel PY, Lawrence M, Brown RK, Stern AM. Stethoscope Acoustics. Circulation 1966; 34: 899.

5. Groom D. Comparative efficiency of stethoscopes. Am Heart J 1964; 68: 220-6.

6. Debiais F, Durand LG, Pibarot P, Guardo R. Time-frequency analysis of heart murmurs. Part I: Parametric modelling and numerical simulations. Med Biol Eng Comput 1997; 35: 474-9.

7. S Spencer C, Pennington K. Nurses with Undiagnosed Hearing Loss: Implications for Practice. Online J Issues Nurs 2015; 20: 6.

8. Strehle E-M, Earle G, Bateman B, Dickinson K. Teaching Medical Students Pediatric Cardiovascular Examination by Telemedicine. Telemed e-Health 2009; 15: 342-6.

9. Garingo A, Friedlich P, Tesoriero L, Patil S, Jackson P, Seri I. The use of mobile robotic telemedicine technology in the neonatal intensive care unit. J Perinatol 2012; 32: 55-63.

10. Ellington LE, Gilman RH, Tielsch JM, Steinhoff M, Figueroa D, Rodriguez S, et al. Computerised lung sound analysis to improve the specificity of paediatric pneumonia diagnosis in resource-poor settings: protocol and methods for an observational study. BMJ Open 2012; 2.

11. Germanakis I, Petridou ET, Varlamis G, Matsoukis IL, Papadopoulou-Legbelou K, Kalmanti M. Skills of primary healthcare physicians in paediatric cardiac auscultation. Acta paediatr 2013; 102: 74-8. 
12. Dahl LB, Hasvold P, Arild E, Hasvold T. Heart murmurs recorded by a sensor based electronic stethoscope and e-mailed for remote assessment. Arch Dis Child 2002; 87: 297.

13. Pyles L, Hemmati P, Pan J, Yu X, Liu K, Wang J, et al. Initial Field Test of a Cloud-Based Cardiac Auscultation System to Determine Murmur Etiology in Rural China. Pediatr Cardiol 2017; 38: 656-62. 14. Portnoy JM, Waller M, De Lurgio S, Dinakar C. Telemedicine is as effective as in-person visits for patients with asthma. Ann Allerg Asthma Im 2016; 117: 241-5.

15. Sola J, Braun F, Muntane E, Verjus C, Bertschi M, Hugon F, et al. Towards an unsupervised device for the diagnosis of childhood pneumonia in low resource settings: automatic segmentation of respiratory sounds. Eng Med Biol Soc Ann 2016; 283-6.

16. Fontaine $\mathrm{E}$, Coste $\mathrm{S}$, Poyat $\mathrm{C}$, Klein $\mathrm{C}$, Lefort $\mathrm{H}$, Leclerc $\mathrm{T}$, et al. In-Flight Auscultation During Medical Air Evacuation: Comparison Between Traditional and Amplified Stethoscopes. Air Med J 2014; 33: 283-5.

17. Tourtier JP, Fontaine E, Coste S, Ramsang S, Schiano P, Viaggi M, et al. In flight auscultation: comparison of electronic and conventional stethoscopes. Am J Emerg Med 2011; 29: 932-5.

18. $3 \mathrm{M} .3 \mathrm{M}^{\mathrm{TM}}$ Littmann $^{\circledR}$ Electronic Stethoscope Model 3200. St. Paul, MN, USA: 3M; 2018. Available from: https://www.littmann.com/3M/en_US/littmann-stethoscopes/

19. Mesquita CT, Reis JC, Simoes LS, Moura EC, Rodrigues GA, Athayde CC, et al. Digital stethoscope as an innovative tool on the teaching of auscultatory skills. Arq Bras Cardiol 2013; 100: 187-9.

20. Elgendi M, Bobhate P, Jain S, Guo L, Rutledge J, Coe Y, et al. Spectral analysis of the heart sounds in children with and without pulmonary artery hypertension. Int J Cardiol 2014; 173: 92-9.

21. Elgendi M, Bobhate P, Jain S, Rutledge J, Coe JY, Zemp R, et al. Time-domain analysis of heart sound intensity in children with and without pulmonary artery hypertension: a pilot study using a digital stethoscope. Pulm Circ 2014; 4: 685-95.

22. Lai Lillian SW, Redington Andrew N, Reinisch Andreas J, Unterberger Michael J, Schriefl Andreas J. Computerized Automatic Diagnosis of Innocent and Pathologic Murmurs in Pediatrics: A Pilot Study. Congenit Heart Dis 2016; 11: 386-95.

23. Khan SI, Ahmed V. Study of adventitious lung sounds of paediatric population using artificial neural network approach. Int J Cur Res Rev 2017; 9: 37-45.

24. Knox C CP, Bolisetty S. An Objective Assessment of Neonatal Bowel Motility Patterns Using a Novel Non-Invasive Technique. J Paediatr Child Health 2014; 50: 1-39.

25. Thinklabs. Thinklabs One Digital Stethoscope. Centennial, CO, USA: Thinklabs; 2015. Available from: https://www.thinklabs.com/. 
26. Ellington LE, Emmanouilidou D, Elhilali M, Gilman RH, Tielsch JM, Chavez MA, et al. Developing a Reference of Normal Lung Sounds in Healthy Peruvian Children. Lung. 2014;192(5):765-73.

27. Scrafford CG, Basnet S, Ansari I, Shrestha L, Shrestha S, Ghimire R, et al. Evaluation of Digital Auscultation to Diagnose Pneumonia in Children 2 to 35 Months of Age in a Clinical Setting in Kathmandu, Nepal: A Prospective Case-Control Study. Pediatr Infect Dis J. 2016;11(2):28-36.

28. Ince DA, Ecevit A, Acar BO, Saracoglu A, Kurt A, Tekindal MA, et al. Noninvasive evaluation of swallowing sound is an effective way of diagnosing feeding maturation in newborn infants. Acta paediatrica 2014; 103: 340-8.

29. Parga JJ, Daland R, Kesavan K, Macey PM, Zeltzer L, Harper RM. A description of externally recorded womb sounds in human subjects during gestation. PLoS One 2018; 13.

30. CliniCloud. Clinicloud Stethoscope Melbourne, Australia: Clinicloud; 2018 [Available from: https://clinicloud.com/store/stethoscope/.

31. Gaertner VD, Kevat AC, Davis PG, Kamlin COF. Evaluation of a digital stethoscope in transitioning term infants after birth. Arch Dis Child-Fetal 2017; 102: 370.

32. Kevat AC, Dawson J, Davis PG, Kamlin COF. Evaluation of a digital stethoscope and smart device technology for assessment of heart rate in the newborn infant. Arch Dis Child-Fetal 2015; 100: 562.

33. Kevat AC, Kalirajah A, Roseby R. Digital stethoscopes compared to standard auscultation for detecting abnormal paediatric breath sounds. Eur J Pediatr 2017; 176: 989-92.

34. HD Medical. ViScope. Silicon Valley, California, USA: HD Medical Inc; 2014. Available from: http://hdmedicalgroup.com/our-products/viscope/.

35. Hsieh BP, Unver K, McNulty E, Schiller NB. The amplitude ratio of the first to second heart sound is reduced in left ventricular systolic dysfunction. Int J Cardiol 2010; 145: 133-5.

36. Eko Devices. Eko. Berkeley, California, USA: Eko Devices; 2018. Available from: https://ekodevices.com/.

37. Behere S, Baffa JM, Penfil S, Slamon N. Real-World Evaluation of the Eko Electronic Teleauscultation System. Pediatr Cardiol 2018.

38. Meditron ASA. The Meditron M30. Oslo, Norway: Meditron ASA; 2001. Available from: http://www.meditron.no/.

39. de Vos JP, Blanckenberg MM. Automated pediatric cardiac auscultation. IEEE Trans Biomed Eng 2007; 54: 244-52. 
40. Mahnke CB, Mulreany MP, Inafuku J, Abbas M, Feingold B, Paolillo JA. Utility of store-andforward pediatric telecardiology evaluation in distinguishing normal from pathologic pediatric heart sounds. Clin Pediatr 2008; 47: 919-25.

41. Germanakis I, Dittrich S, Perakaki R, Kalmanti M. Digital phonocardiography as a screening tool for heart disease in childhood. Acta paediatr 2008; 97: 470-3.

42. Finley JP, Warren AE, Sharratt GP, Amit M. Assessing Children's Heart Sounds at a Distance With Digital Recordings. Pediatrics 2006; 118: 2322.

43. Noponen A-L, Lukkarinen S, Angerla A, Sepponen R. Phono-spectrographic analysis of heart murmur in children. BMC Pediatr 2007; 7: 23.

44. El-Segaier M, Lilja O, Lukkarinen S, Sornmo L, Sepponen R, Pesonen E. Computer-based detection and analysis of heart sound and murmur. Ann Biomed Eng 2005; 33: 937-4245.

45. DeGroff CG, Bhatikar S, Hertzberg J, Shandas R, Valdes-Cruz L, Mahajan RL. Artificial Neural Network-Based Method of Screening Heart Murmurs in Children. Circulation 2001; 103: 2711. 46. Elgendi M, Bobhate P, Jain S, Guo L, Kumar S, Rutledge J, et al. The unique heart sound signature of children with pulmonary artery hypertension. Pulm Circ 2015; 5: 631-9.

47. Pasterkamp H, Powell RE, Sanchez I. Lung sound spectra at standardized air flow in normal infants, children, and adults. Am J Respir Crit Care Med 1996; 154: 424-30.

48. Gross V, Dittmar A, Penzel T, Schuttler F, von Wichert P. The relationship between normal lung sounds, age, and gender. Am J Respir Crit Care Med 2000; 162: 905-9.

49. McCollum ED, Park DE, Watson NL, Buck WC, Bunthi C, Devendra A, et al. Listening panel agreement and characteristics of lung sounds digitally recorded from children aged 1-59 months enrolled in the Pneumonia Etiology Research for Child Health (PERCH) case-control study. BMJ Open Resp Res 2017; 4.

50. Kamlin COF, O'Donnell CPF, Everest NJ, Davis PG, Morley CJ. Accuracy of clinical assessment of infant heart rate in the delivery room. Resuscitation 2006; 71: 319-21.

51. Treston BP, Semberova J, Kernan R, Crothers E, Branagan A, O'Cathain N, et al. Assessment of neonatal heart rate immediately after birth using digital stethoscope, handheld ultrasound and electrocardiography: an observational cohort study. Arch Dis Child-Fetal 2018.

52. Shirota K. Acoustic Analysis of Neonatal Breath Sounds Changes During the Breath Adaptation Period. J Jpn Bronchoesophagol Soc 1998; 49: 442-50.

53. M Hill J, Maloney A, Stephens K, S Adrezin R, Eisenfeld L. Stethoscope for monitoring neonatal abdominal sounds. Proceedings of the IAJC-IJME International Conference 2018.

54. Australian Government. My Health Record. Canberra: Australian Digital Health Agency; 2018. Available from: https://www.myhealthrecord.gov.au/. 
55. Gomes P FS, Castro A, Cruz-Correia R, Coimbra M. A proposal to incorporate digital auscultation and its processing into an existing electronic health record. Proceedings of the International Conference on Health Informatics 2015; 1: 143-50.

56. Chengyu L, David S, Qiao L, Benjamin M, Ricardo Abad J, Francisco JC, et al. An open access database for the evaluation of heart sound algorithms. Physiol Meas 2016; 37: 2181.

57. Vukanovic-Criley JM, Criley S, Warde CM, Boker JR, Guevara-Matheus L, Churchill WH, et al. Competency in cardiac examination skills in medical students, trainees, physicians, and faculty: a multicenter study. Arch Intern Med 2006; 166: 610-6.

58. Mangione S, Nieman LZ. Cardiac auscultatory skills of internal medicine and family practice trainees. A comparison of diagnostic proficiency. JAMA 1997; 278: 717-22.

59. Eslamizadeh G, Barati R. Heart murmur detection based on wavelet transformation and a synergy between artificial neural network and modified neighbor annealing methods. Artif Intell Med 2017; 78: 23-40.

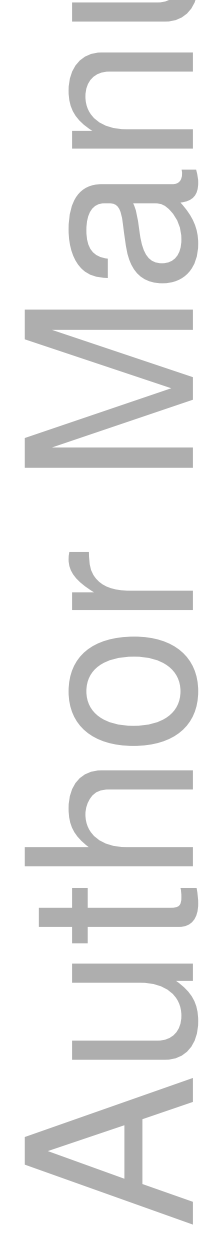

This article is protected by copyright. All rights reserved 
Tables

Table 1: Commercially available Digital Stethoscopes used in published paediatric literature

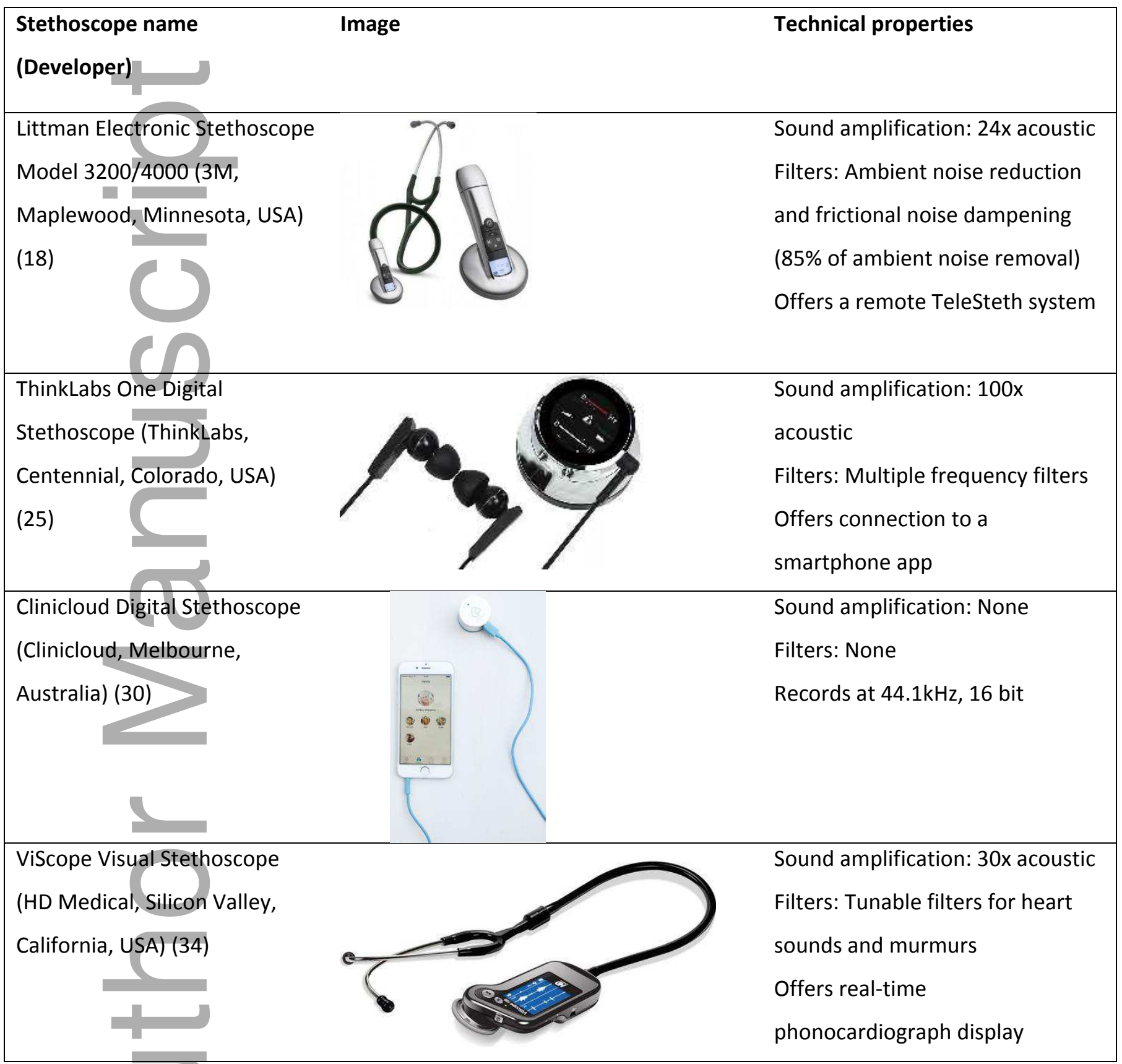



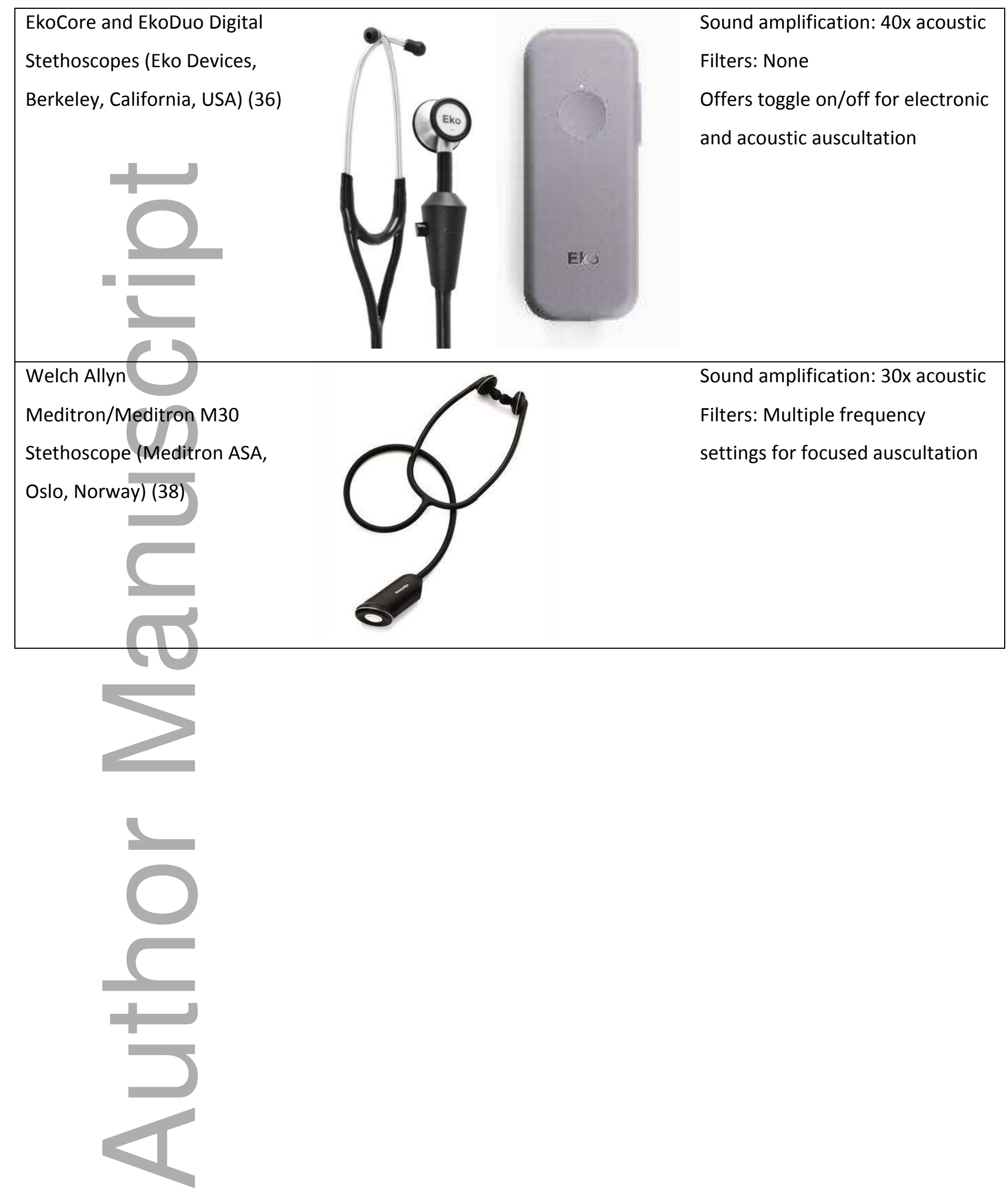
Table 2: Summary of published studies utilising Digital Stethoscopes in children

\begin{tabular}{|c|c|c|c|c|}
\hline Author (Year) & Study Parameter & Population & $\begin{array}{l}\text { Stethoscope } \\
\text { Used }\end{array}$ & Potential use \\
\hline Dahl (2002) & Heart murmurs & $\begin{array}{l}\text { Mean } 5 \text { years ( } 1 \\
\text { month to } 13 \\
\text { years) }\end{array}$ & $\begin{array}{l}\text { The Stethoscope, } \\
\text { Welch Allyn }\end{array}$ & $\begin{array}{l}\text { Telemedicine } \\
\text { feasibility for } \\
\text { differentiating } \\
\text { pathological from } \\
\text { innocent or no } \\
\text { murmur }\end{array}$ \\
\hline Finley (2006) & Heart murmurs & $\begin{array}{l}\text { Range } 1 \text { month } \\
\text { to } 19 \text { years }\end{array}$ & $\begin{array}{l}\text { 3M Littman } \\
\text { Model } 4000\end{array}$ & $\begin{array}{l}\text { Differentiation } \\
\text { between } \\
\text { innocent and } \\
\text { pathological } \\
\text { murmurs }\end{array}$ \\
\hline $\begin{array}{l}\text { Germanakis } \\
(2007)\end{array}$ & $\begin{array}{l}\text { Abnormal heart } \\
\text { sounds }\end{array}$ & $\begin{array}{l}\text { Mean } 4.6 \text { years } \\
\text { (1 month to } 13 \\
\text { years) }\end{array}$ & $\begin{array}{l}\text { The Stethoscope, } \\
\text { Welch Allyn }\end{array}$ & $\begin{array}{l}\text { Possibility for use } \\
\text { as a screening } \\
\text { tool for } \\
\text { recommendation } \\
\text { of patients to } \\
\text { Echocardiogram }\end{array}$ \\
\hline De Vos (2007) & Heart murmurs & $\begin{array}{l}\text { Range } 1 \text { month } \\
\text { to } 16 \text { years }\end{array}$ & $\begin{array}{l}\text { Welch Allyn } \\
\text { Meditron }\end{array}$ & $\begin{array}{l}\text { Discriminate } \\
\text { between } \\
\text { pathological and } \\
\text { innocent } \\
\text { murmurs }\end{array}$ \\
\hline Mahnke (2008) & Heart murmurs & $\begin{array}{l}\text { Mean } 10.2 \text { years } \\
\text { ( } 2 \text { to } 19.5 \text { years) }\end{array}$ & $\begin{array}{l}\text { Handheld STG, } \\
\text { Stethographics }\end{array}$ & $\begin{array}{l}\text { Accurate } \\
\text { differentiation } \\
\text { between } \\
\text { pathological and } \\
\text { innocent } \\
\text { murmurs }\end{array}$ \\
\hline Hill (2008) & $\begin{array}{l}\text { Abdominal } \\
\text { sounds }\end{array}$ & $\begin{array}{l}\text { Premature } \\
\text { infants }\end{array}$ & ThinkLabs & $\begin{array}{l}\text { Method for } \\
\text { identifying or }\end{array}$ \\
\hline
\end{tabular}




\begin{tabular}{|c|c|c|c|c|}
\hline & & & & $\begin{array}{l}\text { monitoring } \\
\text { abdominal } \\
\text { pathology }\end{array}$ \\
\hline Strehle (2009) & Heart sounds & $\begin{array}{l}\text { Range } 8 \text { to } 10 \\
\text { years }\end{array}$ & AMD SmartSteth & $\begin{array}{l}\text { Teaching medical } \\
\text { students cardiac } \\
\text { examination via } \\
\text { telemedicine }\end{array}$ \\
\hline $\begin{array}{l}\text { Repelaer van } \\
\text { Driel (2011) }\end{array}$ & Wheeze & Mean 14 months & ThinkLabs & $\begin{array}{l}\text { Accurate } \\
\text { identification of } \\
\text { wheeze }\end{array}$ \\
\hline Baker (2013) & $\begin{array}{l}\text { Pulmonary } \\
\text { sounds in } \\
\text { abnormal lungs }\end{array}$ & Paediatric & $\begin{array}{l}\text { 3M Littman } \\
\text { Model } 3200\end{array}$ & $\begin{array}{l}\text { Telemedicine for } \\
\text { monitoring } \\
\text { ventilated } \\
\text { patients }\end{array}$ \\
\hline $\begin{array}{l}\text { Emmanouilidou } \\
\text { (2013) }\end{array}$ & $\begin{array}{l}\text { Pulmonary } \\
\text { sounds in normal } \\
\text { lungs }\end{array}$ & Paediatric & ThinkLabs & $\begin{array}{l}\text { Method for } \\
\text { characterisation } \\
\text { of normal breath } \\
\text { sounds }\end{array}$ \\
\hline Ellington (201 & $\begin{array}{l}\text { Pulmonary } \\
\text { sounds in normal } \\
\text { lungs }\end{array}$ & Mean 2.2 years & ThinkLabs & $\begin{array}{l}\text { Method for } \\
\text { characterisation } \\
\text { of normal breath } \\
\text { sounds }\end{array}$ \\
\hline Knox (2014) & Bowel sounds & 1 to 3 days of life & $\begin{array}{l}\text { 3M Littman } \\
\text { Model } 3200\end{array}$ & $\begin{array}{l}\text { Assessment of } \\
\text { bowel motility } \\
\text { patterns in } \\
\text { newborns }\end{array}$ \\
\hline Ince (2014) & Swallowing & $\begin{array}{l}\text { Term mean } 38.4 \\
\text { weeks and } \\
\text { preterm mean } \\
33.7 \text { weeks }\end{array}$ & ThinkLabs & $\begin{array}{l}\text { Characterisation } \\
\text { of swallowing } \\
\text { patterns in } \\
\text { respect to } \\
\text { gestation }\end{array}$ \\
\hline Elgendi (2015) & $\begin{array}{l}\text { Heart sounds } \\
\text { related to } \\
\text { Pulmonary }\end{array}$ & $\begin{array}{l}\text { Median } 7 \text { years } \\
\text { ( } 3 \text { month to } 19 \\
\text { years) }\end{array}$ & $\begin{array}{l}\text { 3M Littman } \\
\text { Model } 3200\end{array}$ & $\begin{array}{l}\text { Method of } \\
\text { diagnosis of PAH }\end{array}$ \\
\hline
\end{tabular}

This article is protected by copyright. All rights reserved 


\begin{tabular}{|c|c|c|c|c|}
\hline & $\begin{array}{l}\text { Artery } \\
\text { Hypertension }\end{array}$ & & & \\
\hline Kevat (2015) & Heart rate & $\begin{array}{l}\text { Infant } 26.7 \text { to } \\
54.7 \text { weeks } \\
\text { corrected } \\
\text { gestation }\end{array}$ & Clinicloud & $\begin{array}{l}\text { Accurate and } \\
\text { clinically easily } \\
\text { useable method } \\
\text { of obtaining HR }\end{array}$ \\
\hline Lai (2016) & Heart murmurs & $\begin{array}{l}\text { Mean } 8 \text { years ( } 1 \\
\text { day to } 18 \text { years) }\end{array}$ & $\begin{array}{l}\text { 3M Littman } \\
\text { Model } 3200\end{array}$ & $\begin{array}{l}\text { Accurate } \\
\text { diagnosis of } \\
\text { pathological } \\
\text { murmurs }\end{array}$ \\
\hline Scrafford (201 & $\begin{array}{l}\text { Pulmonary } \\
\text { sounds } \\
\text { associated with } \\
\text { pneumonia }\end{array}$ & $\begin{array}{l}\text { Range } 2 \text { to } 35 \\
\text { months }\end{array}$ & ThinkLabs & $\begin{array}{l}\text { Accurate } \\
\text { diagnosis of cases } \\
\text { with pneumonia }\end{array}$ \\
\hline Sepehri (2016 & Heart murmurs & $\begin{array}{l}\text { Range } 1 \text { to } 18 \\
\text { years }\end{array}$ & $\begin{array}{l}\text { Welch Allyn } \\
\text { Meditron }\end{array}$ & $\begin{array}{l}\text { Identification of } \\
\text { murmurs }\end{array}$ \\
\hline Kevat (2017) & $\begin{array}{l}\text { Pulmonary } \\
\text { sounds }\end{array}$ & $\begin{array}{l}\text { Mean } 6.7 \text { years } \\
(4.6 \text { to } 17.1)\end{array}$ & Clinicloud & $\begin{array}{l}\text { Detection of } \\
\text { abnormal } \\
\text { pulmonary } \\
\text { sounds (wheeze } \\
\text { and crackles) }\end{array}$ \\
\hline McCollum (20 & $\begin{array}{l}\text { Pulmonary } \\
\text { sounds } \\
\text { associated with } \\
\text { pneumonia }\end{array}$ & $\begin{array}{l}\text { Range } 1 \text { to } 59 \\
\text { months }\end{array}$ & ThinkLabs & $\begin{array}{l}\text { Accurate } \\
\text { diagnosis of cases } \\
\text { with pneumonia }\end{array}$ \\
\hline Gaertner (201 & Heart rate & $\begin{array}{l}\text { Newborn (mean } \\
93 \text { sec post- } \\
\text { birth) }\end{array}$ & Clinicloud & $\begin{array}{l}\text { Accurate and } \\
\text { clinically easily } \\
\text { useable method } \\
\text { of obtaining HR }\end{array}$ \\
\hline Pyles (2017) & Heart murmur & Mean 9.9 years & ThinkLabs & $\begin{array}{l}\text { Accurate } \\
\text { identification of } \\
\text { murmurs over } \\
\text { telemedicine }\end{array}$ \\
\hline Khan (2017) & Adventitious lung & Mean 2 years & 3M Littman & Detection of \\
\hline
\end{tabular}




\begin{tabular}{|c|c|c|c|c|}
\hline & \multicolumn{2}{|l|}{ sounds } & Model 3200 & adventitious \\
\hline Behere (2018) & Heart murmur & Mean 7.8 years & EkoCore & $\begin{array}{l}\text { Accurate } \\
\text { categorisation of } \\
\text { murmurs }\end{array}$ \\
\hline Treston (2018) & Heart rate & $\begin{array}{l}\text { Newborn (mean } \\
120 \text { sec post- } \\
\text { birth) }\end{array}$ & $\begin{array}{l}\text { 3M Littman } \\
\text { Model } 3200\end{array}$ & $\begin{array}{l}\text { Method for } \\
\text { obtaining HR }\end{array}$ \\
\hline
\end{tabular}

This article is protected by copyright. All rights reserved 


\section{University Library}

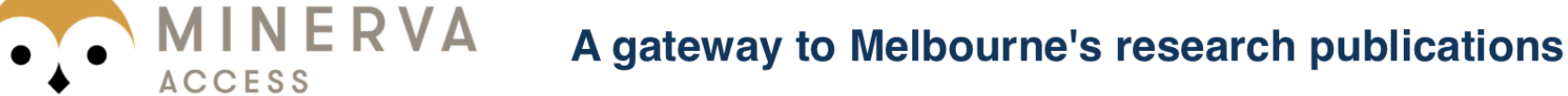

Minerva Access is the Institutional Repository of The University of Melbourne

\section{Author/s:}

Ramanathan, A;Zhou, L;Marzbanrad, F;Roseby, R;Tan, K;Kevat, A;Malhotra, A

Title:

Digital stethoscopes in paediatric medicine

\section{Date:}

2019-05-01

Citation:

Ramanathan, A., Zhou, L., Marzbanrad, F., Roseby, R., Tan, K., Kevat, A. \& Malhotra, A. (2019). Digital stethoscopes in paediatric medicine. ACTA PAEDIATRICA, 108 (5), pp.814-822. https://doi.org/10.1111/apa.14686.

Persistent Link:

http://hdl.handle.net/11343/285285 